\title{
Practices Towards Electronic Medical Records Implementation at MOI Level 5 Hospital Taita Taveta County.
}

\author{
Salim. M. Omambia \\ Kenya Medical Training Centre, P.O. Box 30195-00100 \\ Grace Mbunga \\ Kenya Medical Training Centre, P.O. Box 30195-00100
}

\begin{abstract}
Electronic Medical Records is the use of information and communication technology (ICT) for health care systems. Although Electronic Health Records has been discoverable for decades, hospitals, doctors and other caregivers have been slow to adopt them. Inadequate use of technology leads to a decrease of provision of service quality. Embracing modern technology is one among very many ways of improving efficiency and reducing costs within healthcare organizations. EMR helps to get rid of missing records, duplication of records, minimize the cost of services, saves time and enhances coordination between healthcare providers.
\end{abstract}

\section{INTRODUCTION}

Electronic medical records is a digital version of patients charts used in a clinicians office or the health care facilities (Muchangi and Nzuki, 2014) Though the adoption of EMR is increasing, there is a range in the level of implementation.Electronic medical records adoption model show that by 2017, the number of hospitals achieving stage $5 \& 6$ that is Full R-PACS \& Full CDSS respectively in United States increased by more than $80 \%$ (Ludwick, 2018). Although Electronic health records have been discoverable for decades, hospitals, doctors and other caregivers have been slow to adopt them. This is true even though 74\% of US physicians HER adopters in 2011 said that using their systems enhanced overall patient care and $85 \%$ reported being somewhat or very satisfied with their systems (Jones et al, 2012) Kenya has made tremendous step in ICT. There is limited use of available health information where local health services and population based decision making are concerned, studies done in various developing countries including Mozambique, South Africa and Mongolia suggest that. Health workers at health centres in these countries indicate that Health Information Systems (HISs) such as EMRs are used purely as upward reporting tools and not to support clinician decision making (by physicians and nurses) in patient monitoring and disease management (Muchangi and Nzuki, 2014) .Hindrance to the adoption of hospital information systems in Nigeria included; the high cost of full implementation of a hospital information system, inadequate human capital, corruption, and problems associated with poor infrastructure in Nigeria (Akiyama ,2015) .According to the Kenya National ICT Master Plan (2013/2014-2017/2018) Kenya has experienced significant growth in the ICT sector as demonstrated by the number of telephone lines, Internet Services Providers (ISPs) the number of internet users, broadcasting stations, mobile 
phones and growing competition by mobile service providers. With the rapid growth of ICT in Kenya, EMR adoption in public hospitals has been low. A recent research on the current status of Ehealth in Kenya and Emerging Global Research Trends indicates that adoption of E-health in Kenya is at stage 1 (Lab, Rad, Pharmacy all installed (MoH, 2012) The Kenya Health policy 2012-2030 has a goal attaining the highest possible health standards in a manner responsive to the population needs. The policy aims to achieve this goal through supporting provision of equitable, affordable and quality health and related services at the highest attainable standards to all Kenyans. A research carried out at $\mathrm{KNH}$ recommended that $\mathrm{KNH}$ and $\mathrm{MOH}$ need to have interactive process before implementing any health information system (Omambia et al, 2016)

\section{Study purpose}

To determine practises towards implementation of Electronic Medical Record systems at Moi County Referral Hospital Taita Taveta County.

\section{METHODS}

This study was conducted in Moi District Hospital at Voi sub-county. This is one of the hospitals forming Taita-Taveta County. It is located in Mwangea sub-location, Voi location, the hospital is $330.5 \mathrm{~km}$ from Nairobi via Mombasa Road and $156.2 \mathrm{~km}$ from Mombasa. A target population is the collection of objects which possesses the information required by the researcher and about when an inference is to be made, (Claret et al, 2017).This study comprised all health workers in Voi District hospital. Health workers in Moi hospital make total of approximately 90 workers. These participants were privy to information that was influencing implementation of EMR.

Questionnaire method was used for data collection to obtain a greater depth of response from the respondents of this study. Both open ended and closed ended questions were used to get information from health workers.

Data was obtained manually by use of scientific calculators and Microsoft Excel. Descriptive statistics such as averages, modes and use of percentages were used to analyse the data. Data was then be presented using tables, charts and graphs as diagrammatic presentation and narrative description

The researcher pre-tested the data collection tool to check on the validity and reliability of the results. The pre-tested data was arranged systematically according to the codes of the questionnaires to facilitate analysis. The researcher checked completeness of the questionnaires. Once the questionnaires were complete the data collected was arranged systematically according to the codes of the questionnaires to facilitate analysis. This research involved all the health workers at Moi Level Five Hospital, Taita Taveta County. This research excluded all workers at Moi Level Five Hospital who re not health workers.

Sampling is the process of obtaining a true representative of a certain population. It's also the process of obtaining information about an entire population by examining only a part of it because it was not possible to obtain information from the whole population to successfully achieve the study objectives. Census method was used where all the health workers within Moi Voi Hospital will be involved in the process. 
Omambia, S. M., \& Mbunga, G. (2020) Practices Towards Electronic Medical Records Implementation at MOI Level 5 Hospital Taita Taveta County. Advances in Social Sciences Research Iournal, 7(4) 326-334.

\section{RESULTS AND DISCUSSION}

During the study a total of 90 questionnaires were distributed, 68 were correctly filled and returned which represents a response rate of $76 \%$ Mugenda (2008) argued that a response rate of 50 percent is adequate, a response rate of 60 percent is good, and a response rate of 70 percent is very good. Therefore, the 75 percent response rate reported for this study

From our study majority of the health workers were nurses at (30.88\%) while the least percentage was presented by the doctors and medical social workers at (4.41\%). The mean was 8.5 with a SD of $2.5547 .06 \%$ of the respondents were male while $52.94 \%$ of the respondents were female. Mean $=34, S D=1.41$, ) $58.82 \%$ of the staffs suggested the staff adequacy to be very low while $26.47 \%$ said the staffs adequacy was low. (57.35\%) reported that they have computers in their departments, (42.65\%) are currently not having computers in the departments. $57.37 \%$ of the respondents suggested that the institution had inadequate institutional facilities, $19.12 \%$ said the institution had moderately enough institutional facilities and $23.53 \%$ suggested the institutional facilities were slightly inadequate. Out of the 68 respondents $23(33.82 \%)$ reported that they were fair in computer literacy while $40(58.82 \%)$ reported that they had a high computer literacy level and $5(7.35 \%)$ had a low literacy level in computer.15 (22.05\%) reported that they are fast in typing, $39(57.35 \%)$ reported that they had a fair speed in typing, $5(7.35 \%)$ had a low speed in typing while $9(13.24 \%)$ had a very low speed in typing,31 (45.59\%) reported that they use the internet connection is very low, 7 (10.3\%) no internet connection, 15 (22.06\%) the internet was never high, while $15(15.06 \%)$ internet was always high.93\% of the respondents said there were no IT experts in the institution.85.25\% of the respondents had not received any form of training and only $14.71 \%$ had received training. $11.76 \%$ reported that the hospital was funded by the County government, $36.76 \%$ said the institution was funded by the government, $5.88 \%$ by the NGO's and $41.18 \%$ were not aware.

\section{Organizational Factors Affecting Pratices Towards Emr}

Organizational factors affecting practices towards EMR were prevalent at Moi County Referral Hospital, more than a half of the staffs suggested the staff adequacy, infrastructure availability and resource availability to be very low. This is echoed by (Broekhuis, 2010) finance is major barrier in implementing EMR. The economic aspect is an important factor for many health care providers .Moi County Referral Hospital has done very little to introduce the use of EMR. This ends up leaving the patients and the staffs at a disadvantage to realize the full potential of EMR. Responses to items on organizational factors affecting EMR were as below

Table 1: Results indicating adequacy of institutional facilities factors affecting EMR

\begin{tabular}{|c|c|c|c|}
\hline ADEQUACY OF INSTITUTIONAL FACILITITIES & Frequency & Percent & Cum. Percent \\
\hline Inadequate & 39 & $57.35 \%$ & $57.35 \%$ \\
\hline moderately enough & 13 & $19.12 \%$ & $76.47 \%$ \\
\hline slightly inadequate & 16 & $23.53 \%$ & $100.00 \%$ \\
\hline Total & 68 & $100.00 \%$ & $100.00 \%$ \\
\hline
\end{tabular}


The mean was 22.7 with a SD of $3.57,57.37 \%$ of the respondents suggested that the institution had inadequate institutional facilities

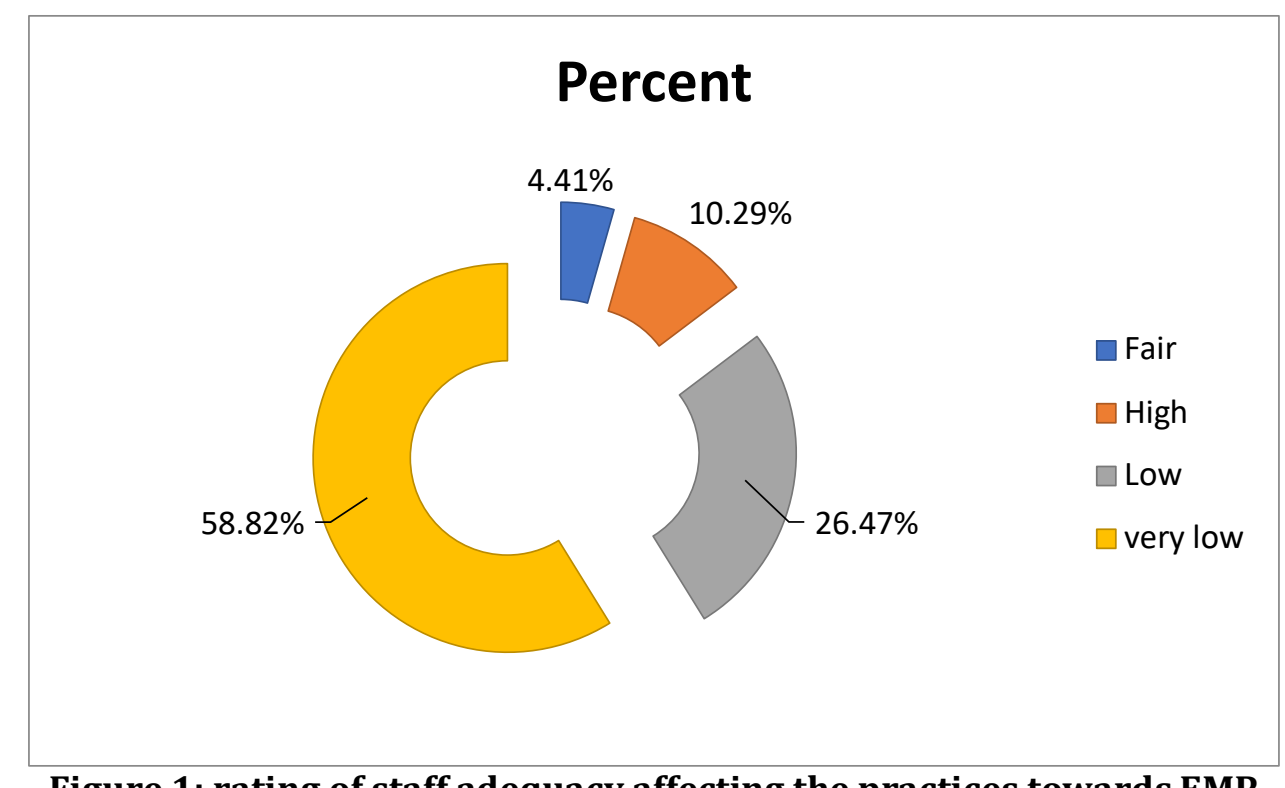

Figure 1: rating of staff adequacy affecting the practices towards EMR

$58.82 \%$ of the staffs suggested the staff adequacy to be very low while $26.47 \%$ said the staffs adequacy was low.

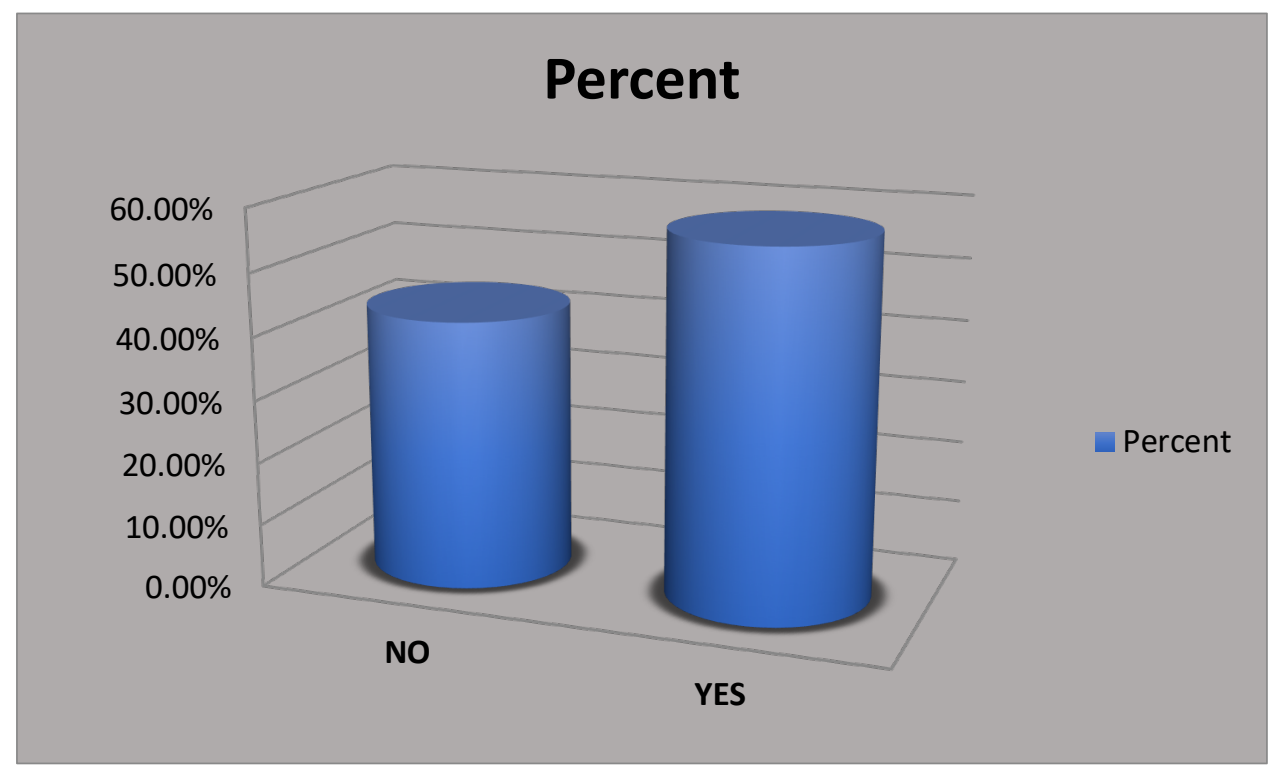

Figure 2 : computer availability effect to practices towars EMR

$(57.35 \%)$ reported that they have computers in their departments, 29 (42.65 \%) are currently not having computers in the departments. 
Omambia, S. M., \& Mbunga, G. (2020) Practices Towards Electronic Medical Records Implementation at MOI Level 5 Hospital Taita Taveta County. Advances in Social Sciences Research Iournal, 7(4) 326-334.

\section{TECHNICAL FACTORS AFFECTING PRACTICES TOWARDS EMR}

As technology changes Information and Communication Technology (ICT) is revolutionizing our life, our ways to interact with each other, and day-to-day life and work. ICTs have made significant impact on healthcare industry in the globe. Its adoption and use, which result into e-healthcare, has transformed the way healthcare services are delivered. Its application in health is described broadly as eHealth, which includes telemedicine1, electronic medical records, and health information systems with decision support, mobile health and E-Learning. At Moi County Referral Hospital there was a weak agreement on technical factors

Table 2: results indicating internet connectivity at Moi County Referral Hospital

\begin{tabular}{|c|c|c|c|}
\hline INTERNET CONNECTION & Frequency & Percent & Cum. Percent \\
\hline always high & 15 & $22.06 \%$ & $22.06 \%$ \\
\hline never high & 15 & $22.06 \%$ & $44.12 \%$ \\
\hline no internet & 7 & $10.29 \%$ & $54.41 \%$ \\
\hline very low & 31 & $45.59 \%$ & $100.00 \%$ \\
\hline Total & 68 & $100.00 \%$ & $100.00 \%$ \\
\hline
\end{tabular}

$(45.59 \%)$ reported that they use the internet connection is very low, 7 (10.3\%) no internet connection, $15(22.06 \%)$ the internet was never high, while 15(15.06\%) internet was always high

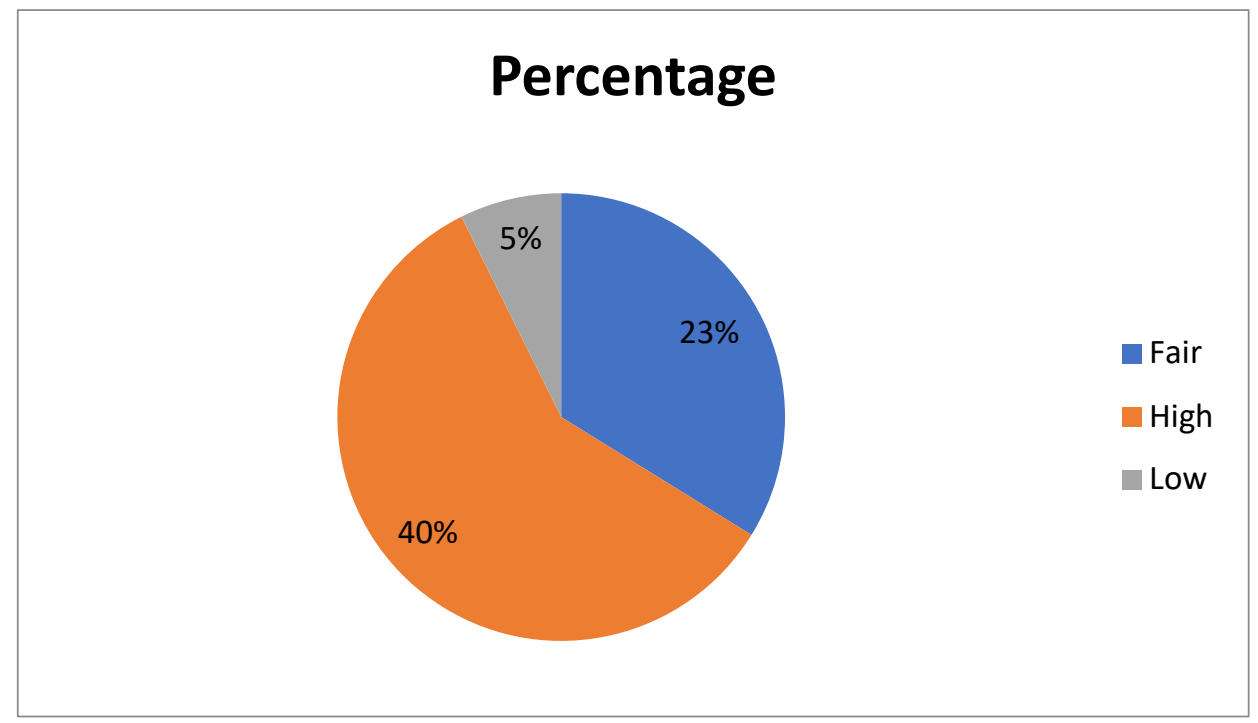

Figure 3: Computer literacy level

Out of the 68 respondents $23(33.82 \%)$ reported that they were fair in computer literacy while 40 $(58.82 \%)$ reported that they had a high computer literacy level and $5(7.35 \%)$ had a low literacy level in computer. From this analysis it shows that majority of the healthcare providers are computer literate which is one of the minimum requirements given in terms to have an EMR system. 


\section{(III) Individual factors affecting practices towards EMR implementation}

The challenges encountered in the implementation of EMR projects have been more with commitments from staff and users of the system. Most of the time, users are ignored in the beginning of the projects but are expected to use it after its completion. Health care providers see the EMR system as complex and inflexible, in addition not highly compatible with their current needs. Some of this was believed to be owing to software interface issues and perceived software immaturity out of $100 \% 83.82 \%$ of the staffs had a positive attitude toward the implementation of EMR while $16.18 \%$ had a negative attitude. This results showed that majority of the healthcare workers had a positive attitude towards working with EMRs and therefore they could understand and embrace the new technology

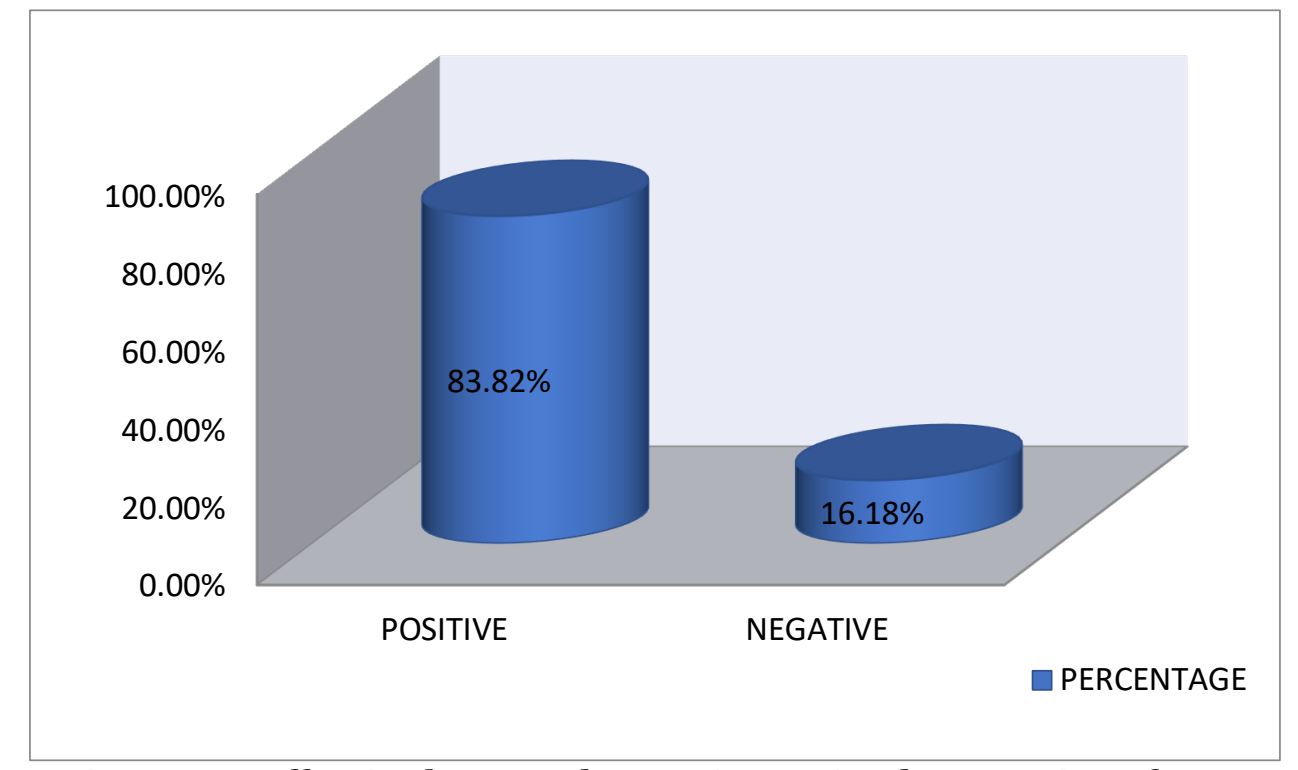

Figure 4: Staff attitude towards practices to implementation of EMR

\section{DISCUSSION}

Study results showed that the usage of EMR technology in Moi level five hospital was low the EMR systems was mostly being used to keep report results. However, it was established that EMR was sometimes used for, medical records retrieval. This finding is supported by Jha et al., (2009) who found out that adoption rate of EMR in hospitals has not been very high due to costs associated with its installation.

One of the objectives of the study was to establish the extent to which organizational factors influences the implementation of Electronic Medical Record systems in Moi county referral hospital at Taita Taveta County, in this study (42.65\%) are currently not having computers in the departments. This results show that majority of the departments have not adopted the EMR system. The findings of this study corresponds to (Makori and Musoke ,2013) which states that cost of computers and lack of computers hinder operation of electronic health amongst hospitals in the rural areas.

The results of this study are also similar to assessments that exposed several challenges to the implementation and use of EMR systems in Kenya. These challenges included: inadequate staff, inability to share clinical information, inability to generate $\mathrm{MOH}$ defined reports and lack of 
Omambia, S. M., \& Mbunga, G. (2020) Practices Towards Electronic Medical Records Implementation at MOI Level 5 Hospital Taita Taveta County. Advances in Social Sciences Research Iournal, 7(4) 326-334.

supportive structures for successful implementations $(\mathrm{MoH}, 2010)$, this is similar to this study findings that the hospital has inadequate number of staffs.

The lack of technical expertise to install and operate EMR technology, cost of EMR technology and inadequate infrastructure were mentioned to be critical factors influencing their use in providing healthcare services to citizens. The findings coincides with Boonstra and Broekhuis (2010) research study that showed that startup costs for EMR system in purchase of hardware and software, selecting and contracting costs and installation expenses were major hindrance towards adoption Physicians and staff resistance is due to lack of computer skills; physicians have insufficient technical knowledge and skills to deal with EMRs, and that this results in resistance.(Meade et al, 2013) this does not partner with the results from this study in which $23(33.82 \%)$ reported that they were fair in computer literacy while $40(58.82 \%)$ reported that they had low literacy level in computer. Omary Z. (2009) low rate of Internet penetration and low bandwidth are among the challenges to EMR adoption, this is contrary to this study findings where there is no internet connection and in the parts that its available it's never high Good typing skills are needed to enter patient medical information, notes and prescriptions into the EMRs, and some physicians lack them, Shachak et al (2016), this conforms to this study results where the health workers have good typing skills.

The study findings show that the respondents had a positive attitude towards implementation of EMRs, could handle the electronic medical records and it could improve the quality of services to patients and clients, this is contrary to a literature by (Hoerbst et al, 2014) which states there was a positive attitude to EMR but providers felt that despite strong media discussion and support, the system had information deficits and other issues on data security. (Omary et al, 2013) literature states that, although initial formal training is depicted favourably by some, insufficient training is often identified as a barrier, either because there is not enough training or because classroom training was ill-suited to physicians' clinical needs and learning styles. Physicians complain about their training and post-sale experience with the vendor. Instead of a training regimen similar to that described in the literature, physicians report that the vendor simply offer one training session of one half to a full day in duration, it's necessary that a follow-up mentorship happens more often so as to fully embrace and implement the EMR system. This is evident in this study finding whereby majority of the health workers neither received any form of training nor any follow-up mentorship.

\section{CONCLUSIONS}

Based on the results and discussions, among the main problems that key informants described during the study, the study examined the extent to which organizational, individual, technical and practices towards implementation influenced the implementation of EMR systems in Moi level five hospitals, Taita Taveta County. The study was successful in addressing the research objectives and the research questions. Following the study findings presented and discussed above, the study conclusions are as follows organizational factors were an important contributor to implementation of EMR system. The results indicated a significant relationship between the factors and adoption of EMR and this meant that adoption of EMR was affected by organizational factors. Further, the findings indicated a weak positive insignificant relationship between individual factors and adoption of EMR and this implied that implementation of EMR was not in any way affected by individual factors. Also, the findings indicated a moderate positive significant relationship between technical factors and adoption of EMR and this meant that adoption of EMR was affected by technical factors. 


\section{RECOMMENDATIONS ON RESEARCH FINDINGS}

Moi County Referral Hospital should including ICT in the curriculum of medical courses as this will give them ownership and confidence to use the technology once they join the practicing field and this will assist in the adoption of EMR by the physicians, after the first formal training of the healthcare practitioners a very good follow-up mentorship should follow to provide the necessary technical support and this will help the healthcare providers to get sufficient experience to be comfortable in the use the EMR system the ministries of health to consider having sufficient health care providers to meet the need of the ever increasing number of patients visiting the health facilities on a daily basis through training more medical personnel and providing adequate incentives to them to enable their working in the facilities. This will assist in reducing the daily workload.

\section{Acknowledgement}

We would like to acknowledge our families and the entire Moi County Referral Hospital.

\section{References}

Akiyama, M. (2015). Transforming healthcare with information technology in Nigeria: A review of policy, people and progress. International Journal of Medical Informatics, 80:157-70.

Broekhuis, M. (2010).Barriers to the acceptance of electronic medical records by physicians from systematic review to taxonomy and interventions. Boonstra and Broekhuis BMC Health Services Research, 10, 231. Retrieved on 24-062015 from http://www.biomedcentral.com/1472-6963/10/231.

Claret, P.-G,Sebanne,M.,,Bobbia,X.,Bonnec,J.-M.,Pommet,S.,Jebali,C.,\&de la Coussaye,J.-E.(2017)First medical contact and physicians opinion after the implementation on an electronic record system. The American Journal of Emergency Medicine 30(7),1235-40.doi:10.1016/J.ajem.2011.06.014

Hoerbst N, Barron Y, Kern LM, Dhopeshwarkar RV, Edwards A, Kaushal R (2014).Attitude and behaviour related to the introduction of EHR among Australia and Germany citizens .International Journal of Medical Informatics79(2010)(81-89)

Jones, S. S., Heaton, P. S., Rudin, R. S., \& Schneider, E. C. (2012). Unraveling the IT productivity paradox-lessons for health care. New England Journal of Medicine, 366(24), 2243-2245.

Ludwick, D. (2018). Primary care physicians" experience with electronic medical records: Barriers to implementation in a fee-for-service environment. International Journal of Telemedicine and Applications. doi:10.1155/2009/853524

Makori, A and Musoke, M., (2013). User issues on the adoption of health informatics systems in level 5 hospitals in Nyanza, Kenya. Interdisciplinary Journal of Contemporary Research in Business; 5(1)

Meade, B., Buckley, D., \& Boland, M. (2013). What factors affect the use of electronic patient records by Irish GPs?. International journal of medical informatics, 78(8), 551-558.

Ministry of Health. (2010). Standards and Guidelines for Electronic Medical record Systems in Kenya. Information Systems.Government of Kenya press.

Ministry of Health. National health system strategic plan(2009-2014). Government of Kenya press

Muchangi, D. M. \& Nzuki, D. (2014).Determinants of Electronic Health in Developing Countries. International Journal of Arts and Commerce, 3 (3), 4960.

Mugenda, A, G (2008). Social Science research; Theory and Principles. Applied Research and Training Services, Kijabe printing Press, Nairobi

Omary, Z., Lupiana, D., Mtenzi, F. \& Wu, B. (2009). Challenges to E-Healthcare Adoption in Developing Countries: A Case Study of Tanzania. First International Conference on Networked Digital Technologies, Ostrava. 
Omambia, S. M., \& Mbunga, G. (2020) Practices Towards Electronic Medical Records Implementation at MOI Level 5 Hospital Taita Taveta County. Advances in Social Sciences Research Iournal, 7(4) 326-334.

Omary, Z., Lupiana, D., Mtenzi, F., \& Wu, B. (2013). Analysis of the Challenges Affecting E- healthcare Adoption in Developing Countries : A Case of Tanzania Analysis of the Challenges Affecting E-healthcare Adoption in Developing Countries : A Case of Tanzania. International Journal of Information Studies, 2(1), 38-50.

S. Omambia and G W ,Odhiambo(2016) The Implementation Criteria of a Health Management Information System.ISJRP.

Shachak, A., Hadas-Dayagi, M., Ziv, A., \& Reis, S. (2016). Primary care physicians' use of an electronic medical record system: a cognitive task analysis. Journal of general internal medicine, 24(3), 341-348. 